\title{
Matrin 3 is a co-factor for HIV-1 Rev in regulating post-transcriptional viral gene expression
}

\author{
Venkat SRK Yedavalli and Kuan-Teh Jeang ${ }^{*}$
}

\begin{abstract}
Post-transcriptional regulation of HIV-1 gene expression is mediated by interactions between viral transcripts and viral/cellular proteins. For HIV-1, post-transcriptional nuclear control allows for the export of intron-containing RNAs which are normally retained in the nucleus. Specific signals on the viral RNAs, such as instability sequences (INS) and Rev responsive element (RRE), are binding sites for viral and cellular factors that serve to regulate RNA-export. The HIV-1 encoded viral Rev protein binds to the RRE found on unspliced and incompletely spliced viral RNAs. Binding by Rev directs the export of these RNAs from the nucleus to the cytoplasm. Previously, Rev co-factors have been found to include cellular factors such as CRM1, DDX3, PIMT and others. In this work, the nuclear matrix protein Matrin 3 is shown to bind Rev/RRE-containing viral RNA. This binding interaction stabilizes unspliced and partially spliced HIV-1 transcripts leading to increased cytoplasmic expression of these viral RNAs.
\end{abstract}

Keywords: Matrin 3, HIV-1, Rev, RNA export, nuclear matrix protein

\section{Background}

The nucleus is a highly organized structure. Chromosomes occupy discrete regions, and specific proteins and nucleic acids are enriched in subnuclear structures such as nuclear lamina, nucleoli, Cajal bodies, nuclear speckles, and paraspeckles [1-6]. The nuclear matrix, a network of underlying filaments in the cell nucleus, shapes the nuclear architecture and functions in genome maintenance, transcription and RNA metabolism [7-17]. Accordingly, the nuclear matrix has important roles in tissue development and cellular proliferation; and the disruption of nuclear organization is often correlated with disease states such as the loss of subnuclear promyelocytic leukemia bodies in acute promyelocytic leukemia [18-21].

HIV-1 gene expression and replication are regulated at transcriptional and post-transcriptional steps including the transactivation of the HIV-1 LTR by Tat [22] and the export of unspliced or partially spliced viral RNAs from the nucleus to the cytoplasm by Rev [23-26]. Rev is a trans-acting viral protein which binds to a cis-acting Rev responsive element (RRE) present in unspliced and

\footnotetext{
* Correspondence: kjeang@niaid.nih.gov
Molecular Virology Section, Laboratory of Molecular Microbiology, National

* Correspondence: kjeang@niaid.nih.gov Institutes of Allergy and Infectious Diseases, the National Institutes of Health, Bethesda, Maryland 20892-0460, USA
}

partially spliced HIV transcripts. Rev has been shown to interact with cellular proteins CRM1, DDX3, PIMT and others to mediate the export of unspliced and singly spliced viral RNAs [27-30]. The mechanism of viral RNA export by Rev is discrete from the export pathways used by fully spliced HIV-1 mRNAs, CTE- (constitutive transport element) dependent RNAs, and cellular mRNAs [31-43].

Recently, numerous studies have implicated the nuclear matrix in gene transcription, RNA splicing, and transport of cellular RNAs $[5,7,9,44,45]$; however, the role of the nuclear matrix in HIV-1 gene expression has been poorly explored [46-48]. Here, we identify Matrin 3 as a key component of factors that mediate the posttranscriptional regulation of HIV-1. Matrin 3 is a highly conserved inner nuclear matrix protein which has been previously shown to play a role in transcription [49-52]. It interacts with other nuclear matrix proteins to form the internal fibrogranular network; it acts in the nuclear retention of promiscuously A-to-I edited RNAs in cooperation with p54(nrb) and PSF [53,54]; it participates in NMDA-induced neuronal death; it modulates the promoter activity of genes proximal to matrix/scaffold attachment region (MAR/SAR) [55]; and it is involved in the repair of double strand breaks [56]. Our current findings implicate that Matrin 3 also influences the 
post-transcriptional expression of a subset of HIV-1 mRNAs.

\section{Results}

Matrin 3 enhances Rev/RRE directed gene expression

We identified Matrin 3 as a PTB-1 (polypyrimidine tract binding protein -1 ) interacting protein in a yeast 2 hybrid assay (Table 1). PTB -1 plays a role in the alternative splicing of cellular mRNAs and has been described to promote the expression of fully spliced HIV-1 transcripts (our unpublished results and [57]). A "PTB-1 associated splicing factor" [58] named PSF has been proposed to inhibit the expression of HIV-1 unspliced/spliced transcripts [59]. We reasoned that like
PSF, Matrin 3 through its association with PTB-1 might modulate HIV-1 gene expression.

To explore a role for Matrin 3 in HIV-1 replication, we measured the effect of over expressed Matrin 3 on viral Tat and Rev mediated gene expression. We expressed Matrin 3 and Tat, either separately or together, in HeLa cells with an HIV-1 LTR luciferase plasmid and measured reporter-expression. As shown in Figure 1A, Matrin 3 did not influence either basal LTR expression or Tat activated expression, suggesting that it does not act at the step of transcription.

We next investigated if Matrin 3 acts at steps post transcription. Rev is required for the cytoplasmic localization of unspliced and partially spliced HIV-1 mRNAs

Table 1 List of Human and Mouse PTB-1 interacting proteins identified by yeast $\mathbf{2}$ hybrid assay.

\begin{tabular}{|c|c|c|}
\hline PTB-1 interacting proteins identified by yeast 2 hybrid assay & Other names/synonyms & Accession \# \\
\hline \multicolumn{3}{|l|}{ A) Interacting with Human PTB-1 } \\
\hline Aladin & AAAS; adracalin & NP_056480 \\
\hline Calcium and integrin binding 1 & $\mathrm{CIB1}$; CIB; kinase-interacting protein 1; KIP1 & NP_006375 \\
\hline Cleavage stimulation factor, 3' pre-RNA, subunit 2, $64 \mathrm{kD}$, tau & CSTF2T; KIAA0689 & NP_056050 \\
\hline Homeodomain-interacting protein kinase 1 isoform 1 & HIPK1; KIAA0630 & NP_938009 \\
\hline Matrin 3 & MATR3 & NP_001181883 \\
\hline poly(rC) binding protein 1 & PCBP1 & NP_006187 \\
\hline RNA binding motif protein 10 & RBM10 & NP_005667 \\
\hline Exportin 1 & CRM1; XPO1 & NP_003391 \\
\hline heterogeneous nuclear ribonucleoprotein $\mathrm{K}$, isoform b & HNRPK & NP_112552 \\
\hline heterogeneous nuclear ribonucleoprotein $\mathrm{L}$ & HNRPL & NP_001524 \\
\hline Raver1 & Raver1 & NP_597709 \\
\hline \multicolumn{3}{|l|}{ A) Interacting with Mouse PTB-1 } \\
\hline arylhydrocarbon receptor nuclear translocator & ARNT, hypoxia-inducible factor 1, beta subunit; dioxin receptor & NP_001659 \\
\hline Calcium and integrin binding 1 & CIB1; CIB; KINASE-INTERACTING PROTEIN 1; KIP1 & NP_006375 \\
\hline DAZ associated protein 2 & DAZAP2 & NP_055579 \\
\hline nuclear receptor coactivator 6 & NCOA6 & NP_054790 \\
\hline Raver1 & Raver1 & NP_597709 \\
\hline Matrin 3 & MATR3 & NP_001181883 \\
\hline RNA binding motif protein 10 & RBM10 & NP_005667 \\
\hline fibrosin-1-like protein & KIAA1545; FBRSL1 & NP_001136113 \\
\hline protein BAT2-like 1 & KIAA0515; BAT2L1 & NP_037450 \\
\hline hexaribonucleotide binding protein 3 & HRNBP3; RBFOX3; FOX3 & NP_001076044 \\
\hline G protein pathway suppressor 2 & GPS2 & NP_004480 \\
\hline proline rich 3 & PRR3 & NP_079539 \\
\hline tripartite motif-containing 8 & TRIM8 & NP_112174 \\
\hline zinc finger, $\mathrm{CCHC}$ domain containing 2 & ZCCHC2; & NP_060212 \\
\hline zinc finger protein $36, \mathrm{C} 3 \mathrm{H}$ type, homolog & ZFP36A, tristetraprolin; NUP475 & NP_003398 \\
\hline neuro-oncological ventral antigen 1 & NOVA1 & NP_002506 \\
\hline neuro-oncological ventral antigen 2 & NOVA2 & NP_002507 \\
\hline
\end{tabular}

Matrin 3 was identified to interact with both Human and Mouse PTB-1 (indicated in bold and italics. The yeast 2 hybrid screening was performed at Myriad Pronet (Utah, USA) using human and mouse PTB-1 as bait. PTB-1 interacting proteins were identified using activation domain fused libraries obtained from human spleen, brain and heart. 


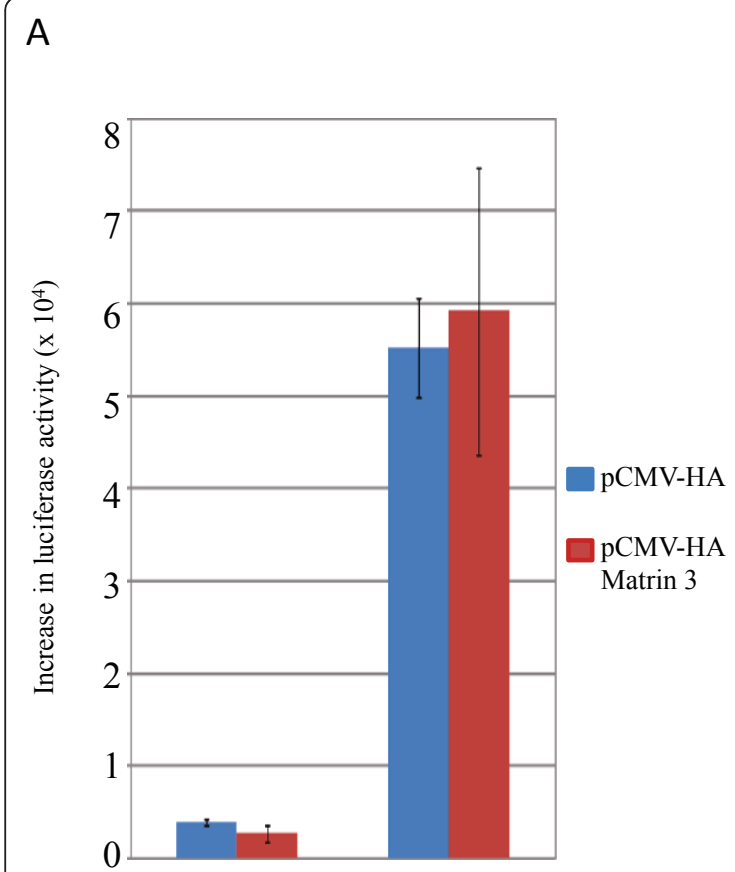

pSV Tat
(-)

(+)
B

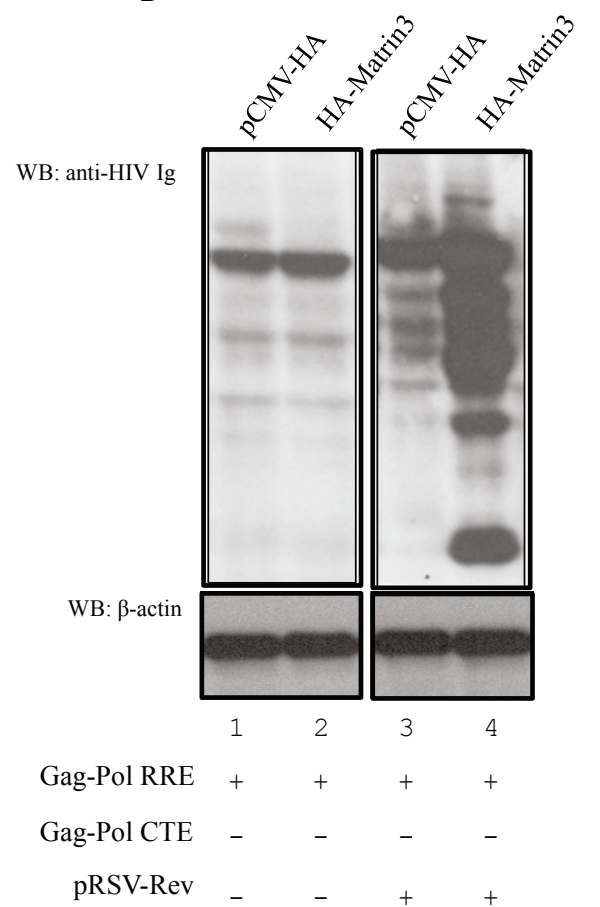

C

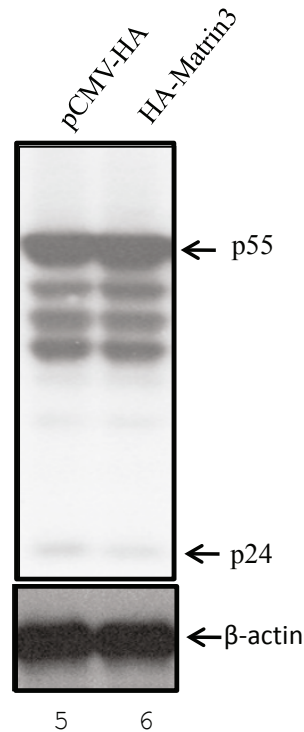

$-\quad-$

$+\quad+$

$+\quad+$

Figure 1 Matrin 3 promotes the expression of Rev dependent RRE containing transcripts. A) HeLa cells were transfected with Matrin 3 and Tat along with HIV-1 LTR luciferase. Luciferase assays performed on cell lysates prepared from these cells did not show any effect of Matrin 3 on Tat dependent LTR transactivation. B) Matrin 3 enhances the expression of RRE containing RNA transcripts in the presence of Rev in HeLa cells. HeLa cells were transfected with $2.0 \mu \mathrm{g}$ of Matrin 3 expression or control plasmid along with $0.5 \mu \mathrm{g}$ of pCMV -GagPol-RRE plasmids in the presence or absence of Rev. HA-Matrin 3 significantly increased the expression of Gag from the reporter construct pCMV-GagPol-RRE in the presence of Rev (compare lanes 2 and 4). C) Gag expression from CTE containing pCMV-GagPol-CTE reporter was not effected by HA-Matrin 3 (compare lanes 5 and 6).

that encode for viral Gag, Env, Vif and Vpu proteins. Rev binds to an RRE-RNA motif in these RNAs [60,61]. Unlike fully spliced viral RNAs, these transcripts contain cis-inhibitory RNA elements which restrict their export from the nucleus into the cytoplasm in the absence of Rev binding to the RRE motif. The binding of Rev to the RRE frees this restriction, and Gag protein expression is thus increased by several fold compared to its expression in the absence of $\operatorname{Rev}[60,61]$.

We checked if Matrin 3 affects Rev-mediated posttranscriptional processes by using a CMV-promoter driven Gag-Pol-RRE expression plasmid as a reporter. HeLa cells were transfected with wild type and mutant Matrin 3 together with pCMV Gag-Pol RRE, as indicated; and 24 hours later, cells were harvested and cell lysates were analyzed by Western blotting. Figure 1B (lanes 1 and 2) shows that Matrin 3 did not alter the expression of Gag in the absence of Rev; however, in the presence of Rev, Matrin 3 increased Gag expression by approximately 10 fold (Figure 1B, lanes 3 and 4). These results support a role for Matrin 3 in Revdependent expression of RRE-containing HIV-1 transcripts.
The CTE is a cis-motif found in RNAs from simple type D retroviruses [32]. It recruits cellular RNA-binding proteins that act to export unspliced or partially spliced viral mRNAs from the nucleus into the cytoplasm $[39,41]$. Artificial placement of the CTE into HIV-1 Gag RNA facilitates its cytoplasmic export and expression, independent of Rev/RRE function [32]. Indeed, CTE and Rev/RRE describe two separate pathways such that the inhibition of either pathway does not affect the export of RNA through the other pathway $[34,35]$. We next assayed a Gag expression vector in which the RRE was replaced with a CTE. Unlike the results from Gal-Pol-RRE (Figure 1b), we found that the over expression of Matrin 3 had no effect on Gag-PolCTE expression (Figure 1C, lanes 5 and 6).

It would be physiologically important to replicate the observations made on the Gag-Pol reporters using a full length HIV-1 infectious molecular clone, pNL4-3. We thus transfected HeLa cells with pNL4-3 and either a control vector or a Matrin 3 expressing vector. One day after transfection, cell lysates were immunoblotted for p24 Gag; and we found that Matrin 3 increased p24 Gag level by approximately 10 fold (Figure 2A). In a 


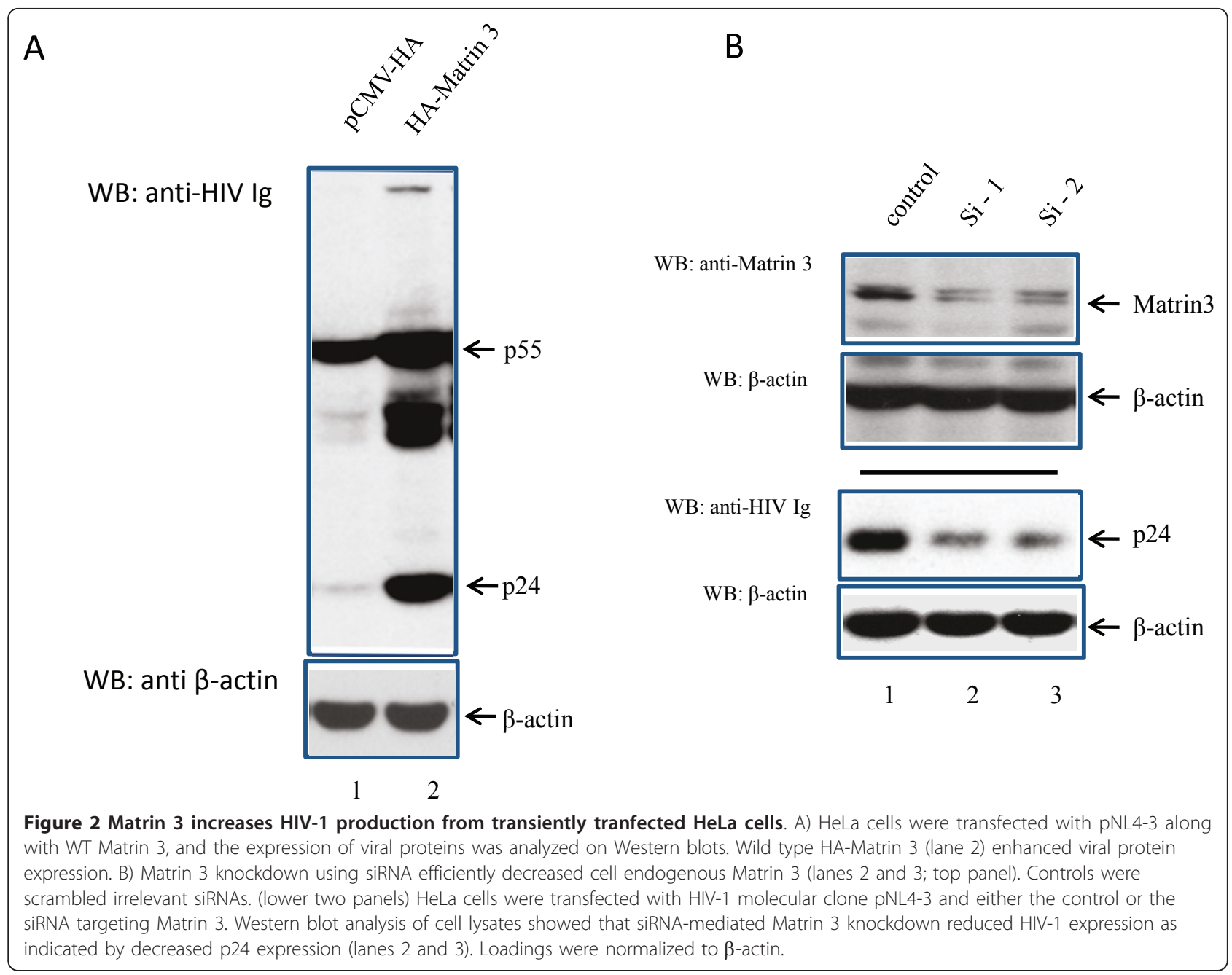

complementary experiment, Matrin 3 RNA was knocked down using specific siRNAs (Figure 2B). siRNAmediated knock down of Matrin 3 decreased HIV-1 p24 Gag expression from pNL4-3 by 3 to 4 fold (Figure 2B). On the other hand, when Matrin 3 expression in knocked down cells was reconstituted (Additional file 1, Figure S1), HIV-1 gene expression was restored. Collectively, the results are consistent with Matrin 3 selectively acting on HIV-1 Rev/RRE - dependent post-transcriptional events.

\section{Matrin 3 interacts with Rev}

How does Matrin 3 affect Rev/RRE-dependent expression? We wondered if Rev, Matrin 3 and RRE-containing RNA are together in a ribonucleoprotein complex. To check this possibility, we transfected and immunoprecipitated HeLa cells with EGFP-Rev with or without Matrin 3 along with versions of HIV-1 Gag p37 constructs (Figure 3A) with or without RRE or CTE [62-64]. The immunoprecipitates were then analyzed by Western blotting using either anti-HA or anti-GFP. Figure 3 shows that there was no interaction between Rev and Matrin 3 (Figure 3B, lanes 7, 9, 10, 11, 12), except when a p37-RRE plasmid was expressed (p37RRE; Figure 3B, lane 8; top). This interaction was not seen when a p37CTE plasmid was used in place of p37RRE (Figure 3B, lanes 9) or when the p37 Gag sequences were codon optimized to make the expression of the RNA transcripts Rev-independent (Figure 3B, lanes 10-12) [62-64]. Thus, our interpretation currently favors that the interaction of Matrin 3 and Rev specifically requires the presence of a Rev-dependent RRE-containing RNA (p37-RRE), but not a Rev-independent RRE-containing RNA (p37-M1-10-RRE). In our experiments, the p37 protein expression levels are similar between p37-RRE, p37-CTE, (Figure 3B, lanes 8-9) and p37M1-10, p37M1-10-RRE and p37-M1-10CTE (Figure 3B, lanes 10-12); hence, the Matrin 3 Rev interaction is not influenced by the amount of p37 protein. 
A

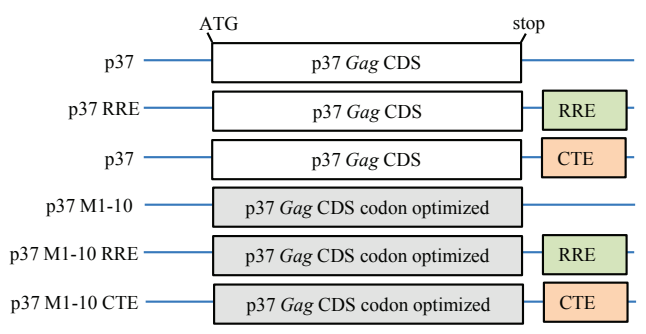

B

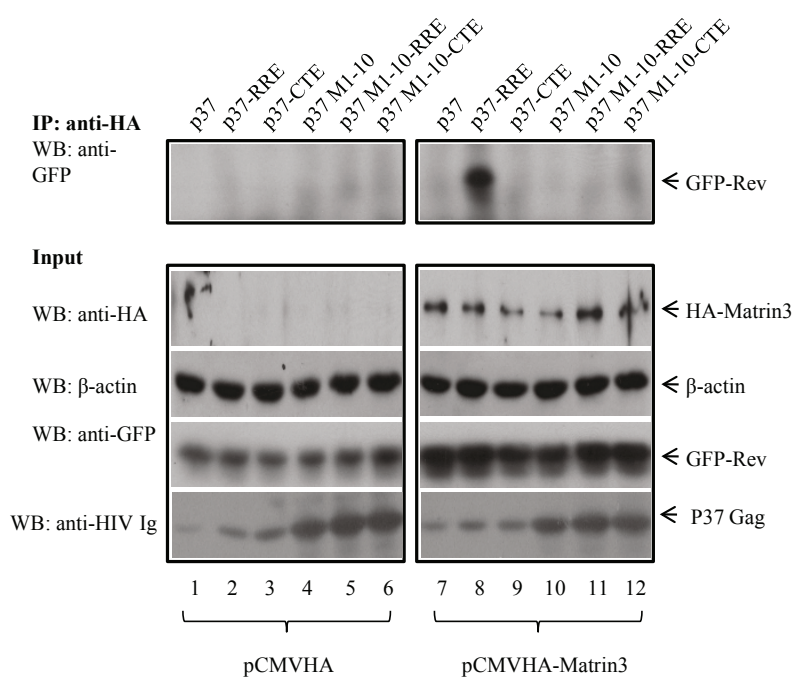

Figure 3 Matrin 3 interacts with Rev in the presence of viral Rev-dependent RRE-containing RNA. A) Schematic representations of the RNAs expressed from the various p37Gag constructs. B) Co-immunoprecipitation of GFP-Rev occurs only in the context of p37-RRE. HeLa cells were transfected with either pCMV-HA (lanes 1-6), or pCMVHA-Matrin 3 (lane 7-12) and GFP-Rev (lanes 1-12) plasmids, along with the indicated versions of a p37Gag expression construct (see panel A and as indicated). Cell lysates were subjected to immunoprecipitation with anti-HA antibody. Western blot analysis of co-immunoprecipitations shows that interaction occurs between Rev and Matrin 3 in the presence of cotransfected p37RRE (lane 8, top panel) construct, but not p37, p37CTE, or codon optimized P37 Gag constructs that are Rev-independent (lanes 7 and 9-12, top panel). Lower two panels show the expression of Rev and Matrin 3 in cell lysates used for the immunoprecipitations, and the second panel from the top shows HA-Matrin 3 proteins recovered by the co-immunoprecipitations.

Matrin 3 RNA recognition motifs (RRM) 3 are required for activity on Rev/RRE

The above results are consistent with Matrin 3 associating with Rev and RRE-RNA to facilitate expression. A prediction from these results is that an RNA-binding competent Matrin 3 is needed for its activity on HIV-1 RNAs. To address this notion, we constructed two Matrin 3 deletion mutants as indicated in Figure 4A. Matrin 3 is an 847amino acid protein with two RNA recognition motifs (RRM) contained in amino acids 399 to 567, and a bipartite NLS in amino acids 586 - 612. The RRMs are required for Matrin 3 to bind RNA. The two Matrin 3 deletion mutants expressed well in human cells (Figure 4B). When both were assayed in co-transfections with pNL4-3 (Figure 4C) and compared to the activity of wild type Matrin 3, neither mutant was proficient in activating HIV-1 as measured by Gag p24 expression (Figure 4C). The mutants showed expected localization in the nucleus (Additional file 2 Figure S2). The results from the RRM mutants are consistent with the notion that RNA-binding by Matrin 3 is required for its HIV-1 function.

Matrin 3 increases the stability and nuclear export of HIV1 RRE-containing transcripts

One consequence of Matrin 3 binding to RNA could be the stabilization of RRE-containing transcript. To check this possibility, we compared the expression of
RRE containing transcripts in HeLa cells transfected with HA-Matrin 3 (Figure 5). In HIV-1, the unspliced, partially spliced and fully spliced RNAs can be categorized into three groups based on their sizes. The $\sim 9 \mathrm{~kb}$ unspliced RNA serves as the genomic RNA and also encodes the Gag, Gag-Pol fusion proteins. A set of $\sim 4$ $\mathrm{kb}$, singly spliced mRNAs encode for Env, Vpr, Vif and Vpu. A group of fully spliced $\sim 1.8 \mathrm{~kb}$ mRNAs encode Tat, Rev and Nef. The $9 \mathrm{~kb}$ and $4 \mathrm{~kb}$ classes of mRNAs contain the RRE element while the $1.8 \mathrm{~kb}$ mRNAs do not. We analyzed the effect of Matrin 3 on the expression of the $9 \mathrm{~kb}$ and $4 \mathrm{~kb}$ transcripts compared to the Rev/RRE independent $1.8 \mathrm{~kb}$ group of RNA. HeLa cells were transfected with pNL4-3 and Matrin 3 for this analysis, and we analyzed $20 \mu \mathrm{g}$ of total RNA by Northern blotting (Figure 5A). There was an increase, in the HA-Matrin 3 transfected cells, in the $9 \mathrm{~kb}$ unspliced and $4 \mathrm{~kb}$ singly-spliced RNA transcripts (which contain RRE; ratios of $1: 2.9$ and 1:2.3 respectively; Figure 5A, bottom), compared to the fully spliced $1.8 \mathrm{~kb}$ RNA (which does not contain RRE; a ratio of $1: 1.2$; Figure $5 \mathrm{~A}$, bottom).

We next investigated the consequence of increased Matrin 3 expression on cytoplasmic distribution of unspliced versus spliced viral RNAs. We co-transfected HeLa cells with pNL4-3 and Matrin 3, and fractionated cellular RNAs into total, cytoplasmic, or nuclear 
A

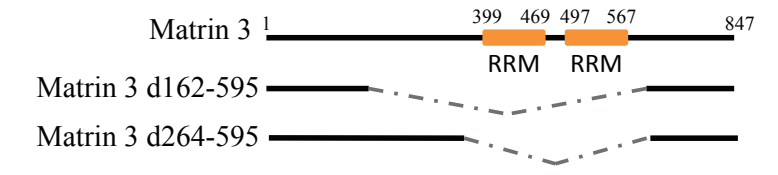

$\mathrm{B}$

WB: anti $\beta$-Actin

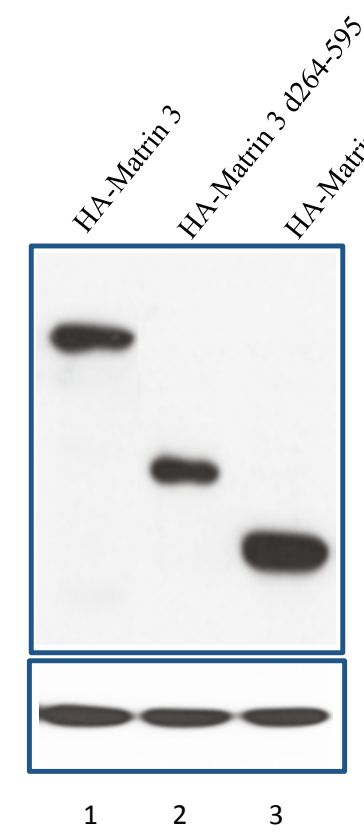

$\mathrm{C}$

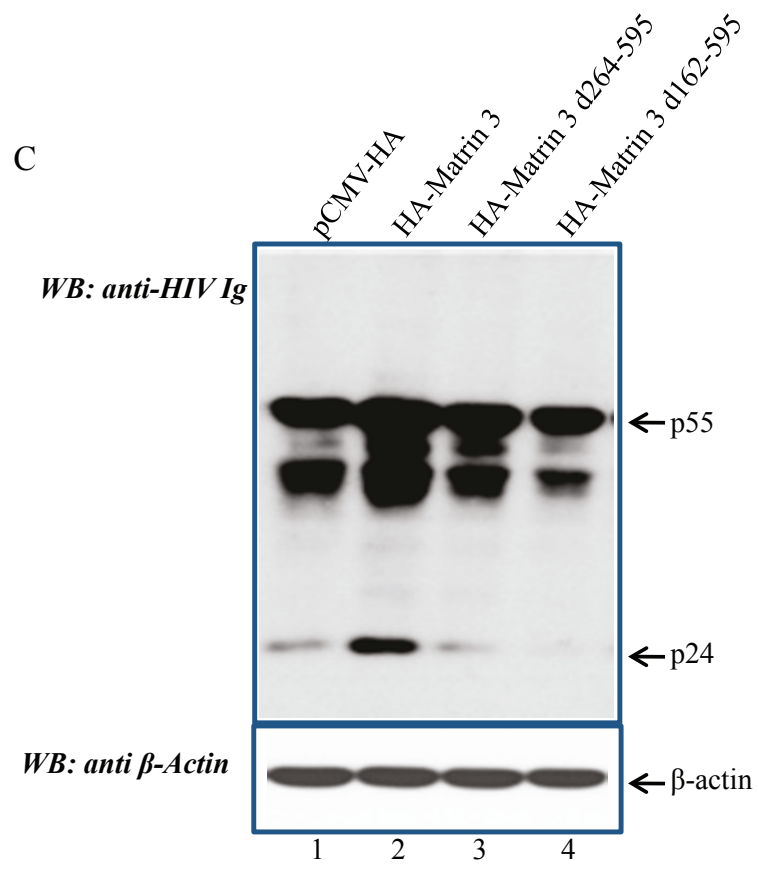

Figure 4 Matrin 3 RRMs are required for activity on HIV-1 RNA. A) Schematic representations of the RRM deletion mutants of Matrin 3. B) Western blot verification of the comparable expression of transfected Matrin 3 deletion mutants. Loadings were normalized to $\beta$-actin (bottom panel). C) Expression of wild type HA-Matrin 3 (lane 2), but not HA-Matrin 3 d264-595 (lane 3) nor HA-Matrin 3 d162-595 (lane 4), which lack the RRMs activated HIV-1 gene expression as measured by viral p55 or p24 levels.

constituents. We isolated the RNAs from these fractions and analyzed them by qRT-PCR for the levels of unspliced and spliced RNAs using primers specific for the $9 \mathrm{~kb}$ or the $1.8 \mathrm{~kb}$ viral RNA. We used GAPDH as a normalization control for our fractionation (GAPDH; Figure 5B). Consistent with the Northern blot results, there was a 3 fold increase in expression of unspliced viral RNA in the cells (total 9 kb; Figure 5B), but interestingly the amount of $9 \mathrm{~kb}$ viral RNA distributed into the cytoplasm of pCMV-HA-Matrin 3 expressing cells was 10 fold higher than that found in PCMV-HA expressing cells (cytoplasmic $9 \mathrm{~kb}$; Figure 5B; also see Additional file 3, Figure S3). By contrast, the distribution and expression of spliced RNA remained unchanged in the presence of increased Matrin 3 expression (1.8 kb; Figure 5B). These results are consistent with the interpretation that Matrin 3 can selectively stabilize and increase the nuclear to cytoplasmic distribution of unspliced $9 \mathrm{~kb}$ vs. spliced $1.8 \mathrm{~kb}$ HIV-1 RNAs.

\section{Discussion}

Here, we have shown that nuclear matrix protein Matrin 3 influences the expression of HIV-1 RRE-containing mRNAs. Matrin 3 acts post-transcriptionally via Rev/ RRE to increase the expression of HIV-1 Rev/RRE dependent unspliced or partially spliced transcripts. This activity requires Matrin 3 to bind Rev-dependent RREcontaining RNA and appears to lead to the stabilization and nuclear to cytoplasmic export of RRE-containing HIV-1 transcripts.

Previously it was shown that Matrin 3 exists in cells complexed with PSF (PTBP associated splicing factor) and nrbp54 [53,65-67]. Others have found that PSF binds to instability elements (INS) contained within the HIV-1 transcripts and suppresses the expression of these RNAs [59]. The INS elements are primarily present in the RRE-containing unspliced and partially spliced viral transcripts $[31,64,68-72]$. It is possible that some of the effects that we have observed from Matrin 3 may be due to its interaction with PSF and p54nrb. 
A
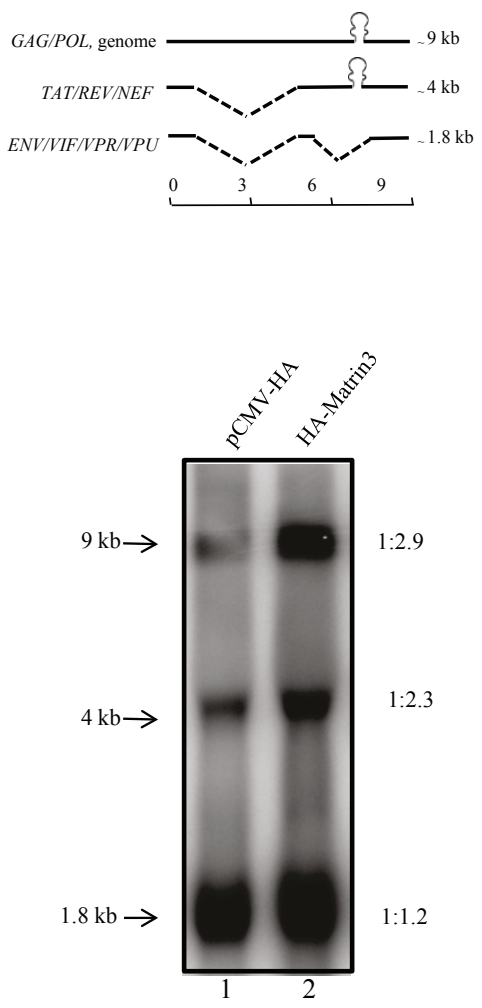

B
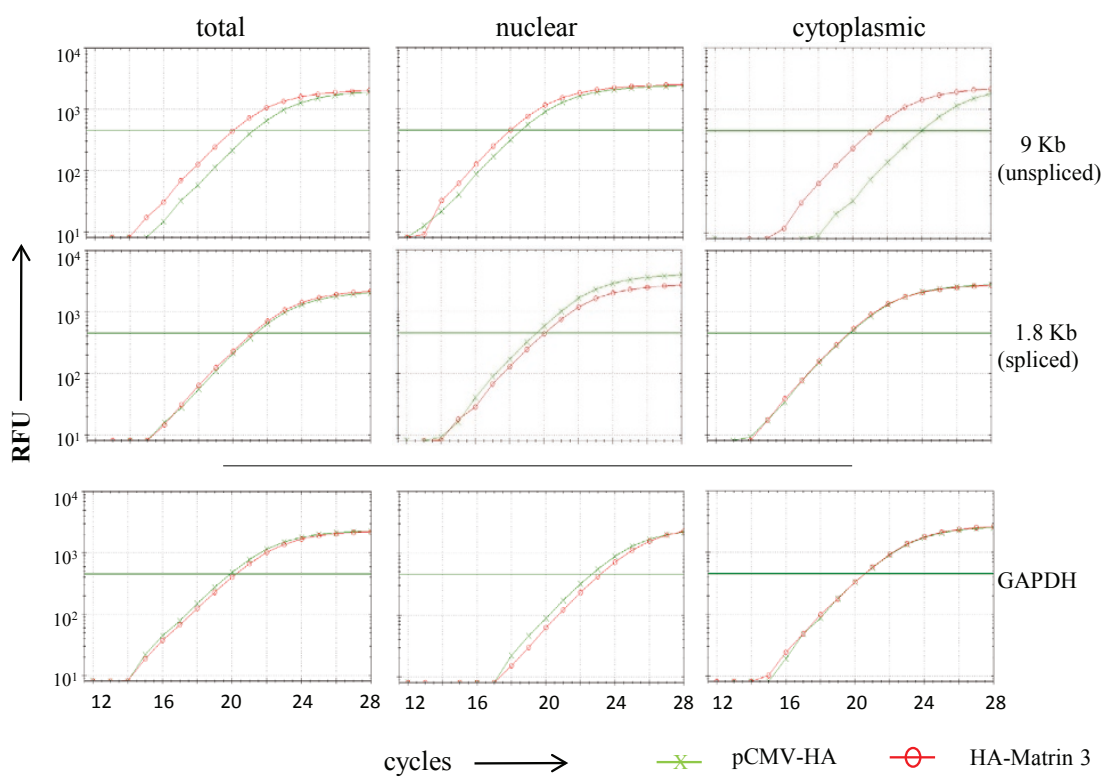

Figure 5 Matrin 3 stabilizes RRE-containing RNA. A) (top) Schematic representations of the differently sized mRNA transcripts produced during HIV-1 replication. The $9 \mathrm{~kb}$ (unspliced) and $4 \mathrm{~kb}$ (singly spliced) viral transcripts contain the RRE cis-element and require Rev protein for expression. (bottom) HeLa cells were transfected with HIV-1 molecular clone pNL4-3 and either pCMV-HA or HA-Matrin 3 plasmids. Northern blot analysis of whole cell RNA demonstrated increased expression of unspliced $9 \mathrm{~kb} \mathrm{HIV}-1$ transcript (lane 2). Relative changes in the expression of 9 $\mathrm{kb}$ and $1.8 \mathrm{~kb}$ HIV-1 RNAs in cells, with and without Matrin 3, are shown by the numbers on the right. B) Matrin 3 increased the stability and promoted the nuclear export of HIV-1 unspliced RNA. HeLa cells were transfected with pNL4-3 with (red) or without (green) Matrin 3. RNA was isolated from whole cell lysates as well as nuclear and cytoplasmic fractions. qRT-PCR analysis of HIV-1 RNA was performed using primers specific for spliced and unspliced viral transcripts [29]. Transfection of Matrin 3 (red) resulted in modestly increased amounts of HIV-1 unspliced transcripts in the cells (top left panel, total), and a much larger increase in the distribution of unspliced HIV-1 transcripts into cytoplasm (top right panel, cytoplasmic). As control, Matrin 3 did not affect the stability or the distribution of GAPDH mRNA (bottom panels, GAPDH).

That Matrin 3 might counter the reported PSF-suppression of RNA expression has not been explored here, but it remains important to establish and clarify this mechanistic interaction in the future.

Our results are compatible with a model in which Matrin 3 binds to RRE containing transcripts and stabilizes them in the presence of Rev, which then directs these viral transcripts for export out of the nucleus. This interpretation is supported by our observation that Rev - Matrin 3 interaction is RRE-RNA dependent, and Matrin 3 activity requires the presence of Rev and RREcontaining RNA. Further experiments are needed to answer the mechanistic details of how Matrin 3 and Rev cooperate in their interactions with RRE-containing RNA. One intriguing finding is that Matrin 3 has been identified as a constituent of the nuclear pore proteomes
[73]; this localization would be compatible with Matrin 3 being a part of an RNP-complex that exits the nucleus into the cytoplasm through the nuclear pore. Also of interest, Bushman et al. [74] recently performed a metaanalysis of published genome-wide siRNA screening of cellular factors important for HIV-1 replication. They used a graph theory clustering algorithm (MCODE) to assemble a HIV-1 host interactome in which nuclear matrix structure (Matrin 3) was identified as an interactor with the molecular chaperone cluster identified by siRNA-screening as involved in the assembly of viral proteins. Our evidence here for a role of Matrin 3 in HIV-1 post-transcriptional RNA expression is consistent with the above analysis. In conclusion, the implication of Matrin 3 as an additional Rev co-factor adds further complexity to the understanding of post-transcriptional 
regulation of unspliced/partially spliced HIV-1 RNA. Although it remains to be established, Matrin 3 may be a cellular factor that counters the nuclear retention through INS elements of HIV-1 unspliced/partially spliced RNAs.

\section{Materials and methods Plasmids}

Full-length Matrin 3 clone was purchased from Open Biosystems and cloned into PCMV-HA vector (Clontech) by PCR. HIV-1 LTR luciferase plasmid, pCMVNL-GagPol-RRE and pCMV-NL-GagPol-CTE were from E. Freed and D. Rekosh. Plasmids p37 and p37RRE were kindly provided by B. Felber [64] and cloned into pcDNA3.

\section{Cell Culture, Transfection, and Reporter Assays}

Cell propagation, transfection, qRT-PCR and reporter assays were as described previously [28,29]. All transfections were repeated three or more times and were normalized to $\beta$-galactosidase activity expressed from a cotransfected pCMV- $\beta$ (Clontech).

\section{Antibodies}

Mouse monoclonal anti-HA (Sigma Chemical); mouse monoclonal Matrin 3, (Abcam) and rabbit anti-GFP and anti-HA (Cell Sciences) are commercially available.

\section{Western Blotting, and Immunoprecipitation}

Western blotting and immunoprecipitation were performed as described previously $[28,29]$. Briefly, the cells were washed twice with PBS and lysed with sample buffer [100 mMTris (pH6.8), 4\%SDS, 20\% glycerol, $5 \% \beta$ mercaptoethanol, and $0.05 \%$ bromophenol blue]. Cell lysates were boiled for 10 minutes, and loaded onto a SDS/PAGE gel and electrophoresed. The gel was electroblotted onto Immobilon-P membranes (Millipore) and probed with the primary antibodies, followed by incubation with anti-rabbit, anti-mouse, or anti-human alkaline phosphatase-conjugated secondary antibody and detected using a chemiluminescence substrate (Applied Biosystems).

\section{RNA isolation, Northern blotting and qRT-PCR}

Total RNA from cells was extracted with Tri-Reagent (Sigma-Aldrich). Nuclear and cytoplasmic RNAs were isolated by cell fractionation (Paris Kit; Applied Biosystems), and RNA was isolated with Tri-Reagent. Northern blots were performed as described previously [28]. Extracted RNA was analyzed by qRT-PCR using the iScript OneStep RT-PCR Kit with SYBR Green (Bio-Rad) according to manufacturer's instructions. Samples were reverse-transcribed at $50^{\circ} \mathrm{C}$ for 30 minutes, and amplification was performed after an initial step at $95^{\circ} \mathrm{C}$ for 10 minutes, followed by $20-40$ cycles at $95^{\circ} \mathrm{C}$ for $30 \mathrm{~s}, 55^{\circ} \mathrm{C}$ for $30 \mathrm{~s}$, and $72^{\circ} \mathrm{C}$ for $60 \mathrm{~s}$. The primers and their sequences used in the analyses have been previously described [29]. Primers for unspliced transcripts were Primer A 5'GTCTCTCTGGTTAGACCAG-3', Primer C 5'-CTAGTCAAAATTTTTGGCGTACTC-3' and primer A and sj4.7A 5'- TTGGGAGGTGGGTTGCTTTGATAGAG-3 for spliced $2 \mathrm{~Kb}$ transcript. For GAPDH forward 5' CTCTGCTCCTCCTGTTCGAC 3' and GAPDH reverse 5' TTAAAAGCAGCCCTGGTGAC 3' primers were used.

\section{Co-immunoprecipitation}

Co-immunoprecipitation assay has been described previously $[28,29]$. Cell lysates were prepared in RIPA buffer [Tris-buffered saline ( $\mathrm{pH}$ 8.0) containing 1\% Triton X-100 or Nonidet P-40, $1 \mathrm{mg}$ of BSA $/ \mathrm{mL}$, and $1 \mathrm{mM}$ EDTA] containing (phenylmethylsulfonyl fluoride and aprotinin $10 \mu \mathrm{g} / \mathrm{mL}$ ), $0.5 \%$ sodium deoxycholate, and $0.1 \%$ SDS. Cell lysates were prepared and incubated at $4^{\circ} \mathrm{C}$ overnight with the indicated antibodies and immune complexes were pulled down using protein G-agarose beads and analyzed by Western blotting.

\section{Additional material}

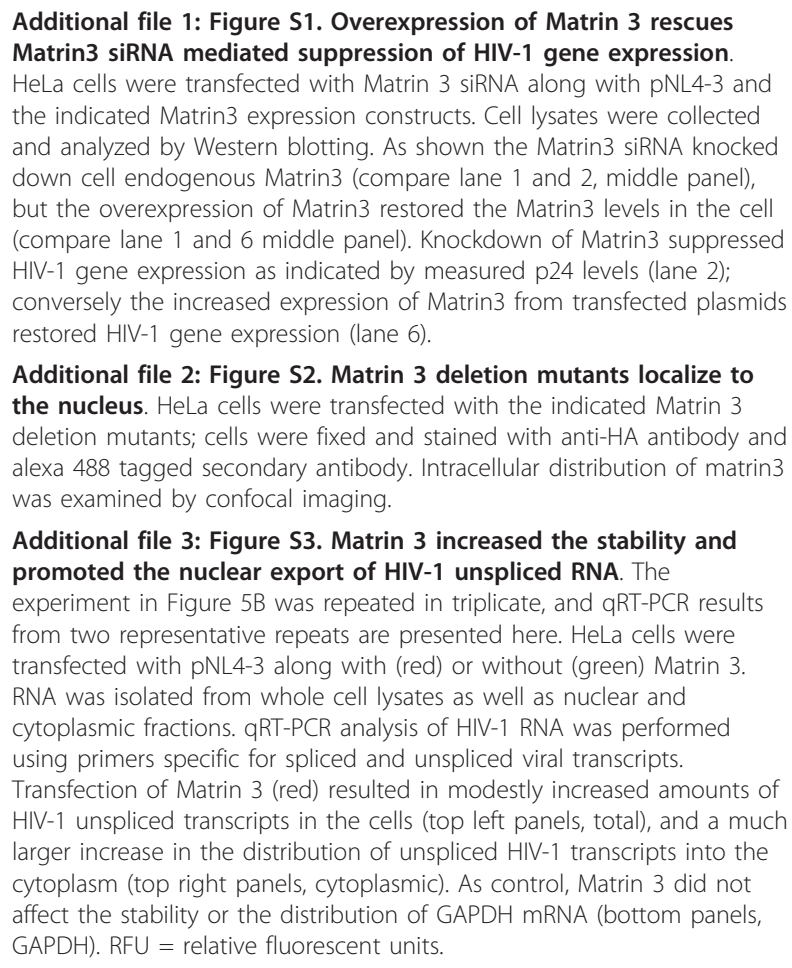

Additional file 2: Figure S2. Matrin 3 deletion mutants localize to the nucleus. HeLa cells were transfected with the indicated Matrin 3 deletion mutants; cells were fixed and stained with anti-HA antibody and alexa 488 tagged secondary antibody. Intracellular distribution of matrin3 was examined by confocal imaging.

Additional file 3: Figure S3. Matrin 3 increased the stability and promoted the nuclear export of HIV-1 unspliced RNA. The experiment in Figure 5B was repeated in triplicate, and GRT-PCR results from two representative repeats are presented here. HeLa cells were transfected with pNL4-3 along with (red) or without (green) Matrin 3. RNA was isolated from whole cell lysates as well as nuclear and cytoplasmic fractions. qRT-PCR analysis of HIV-1 RNA was performed using primers specific for spliced and unspliced viral transcripts.

Transfection of Matrin 3 (red) resulted in modestly increased amounts of HIV-1 unspliced transcripts in the cells (top left panels, total), and a much larger increase in the distribution of unspliced HIV-1 transcripts into the cytoplasm (top right panels, cytoplasmic). As control, Matrin 3 did not affect the stability or the distribution of GAPDH mRNA (bottom panels, GAPDH). RFU = relative fluorescent units.

\section{Acknowledgements}

Work in KTJ's laboratory was supported in part by Intramural funds from NIAID, and by the Intramural AIDS Targeted Antiviral Program (IATAP) from the office of the Director, NIH. We thank members of KTJ's laboratory for 
reading and commenting on the manuscript, and Barbara Felber for sharing several critical reagents. We are grateful to Anna Kula and Alessandro Marcello for sharing data in their paper prior to publication [75].

\section{Authors' contributions}

VSY performed all the experiments. VSY and KTJ designed the experiments and wrote the manuscript. Both authors read and approved the final manuscript.

\section{Competing interests}

The authors declare that they have no competing interests.

Received: 16 February 2011 Accepted: 20 July 2011

Published: 20 July 2011

\section{References}

1. Vlcek S, Dechat T, Foisner R: Nuclear envelope and nuclear matrix: interactions and dynamics. Cell Mol Life Sci 2001, 58:1758-1765.

2. Baxter J, Merkenschlager M, Fisher AG: Nuclear organisation and gene expression. Curr Opin Cell Biol 2002, 14:372-376.

3. Stein GS, Lian JB, Montecino M, Stein JL, van Wijnen AJ, Javed A, Pratap J, Choi J, Zaidi SK, Gutierrez S, et al: Nuclear microenvironments support physiological control of gene expression. Chromosome Res 2003, 11:527-536.

4. Stein GS: Gene expression in nuclear microenvironments for biological control and cancer. Cancer Biol Ther 2007, 6:1817-1821.

5. Stein GS, Davie JR, Knowlton JR, Zaidi SK: Nuclear microenvironments and cancer. J Cell Biochem 2008, 104:1949-1952.

6. Fedorova E, Zink D: Nuclear architecture and gene regulation. Biochim Biophys Acta 2008, 1783:2174-2184.

7. Berezney R, Coffey DS: Nuclear protein matrix: association with newly synthesized DNA. Science 1975, 189:291-293.

8. Cook PR: The nucleoskeleton: artefact, passive framework or active site? J Cell Sci 1988, 90(Pt 1):1-6.

9. Nickerson JA: Nuclear dreams: the malignant alteration of nuclear architecture. J Cell Biochem 1998, 70:172-180.

10. Wei X, Samarabandu J, Devdhar RS, Siegel AJ, Acharya R, Berezney R: Segregation of transcription and replication sites into higher order domains. Science 1998, 281:1502-1506.

11. Berezney R: Regulating the mammalian genome: the role of nuclear architecture. Adv Enzyme Regul 2002, 42:39-52.

12. Stein GS, Zaidi SK, Braastad CD, Montecino M, van Wijnen AJ, Choi JY, Stein $J$, Lian JB, Javed A: Functional architecture of the nucleus: organizing the regulatory machinery for gene expression, replication and repair. Trends Cell Biol 2003, 13:584-592.

13. Zaidi SK, Young DW, Choi JY, Pratap J, Javed A, Montecino M, Stein JL, van Wijnen AJ, Lian JB, Stein GS: The dynamic organization of gene-regulatory machinery in nuclear microenvironments. EMBO Rep 2005, 6:128-133.

14. Misteli T: Beyond the sequence: cellular organization of genome function. Cell 2007, 128:787-800.

15. Lanctot C, Cheutin T, Cremer M, Cavalli G, Cremer T: Dynamic genome architecture in the nuclear space: regulation of gene expression in three dimensions. Nat Rev Genet 2007, 8:104-115.

16. Malyavantham KS, Bhattacharya S, Barbeitos M, Mukherjee L, Xu J, Fackelmayer FO, Berezney R: Identifying functional neighborhoods within the cell nucleus: proximity analysis of early S-phase replicating chromatin domains to sites of transcription, RNA polymerase II, HP1gamma, matrin 3 and SAF-A. J Cell Biochem 2008, 105:391-403.

17. Cohen TV, Hernandez L, Stewart CL: Functions of the nuclear envelope and lamina in development and disease. Biochem Soc Trans 2008, 36:1329-1334.

18. Nelson WG, Pienta KJ, Barrack ER, Coffey DS: The role of the nuclear matrix in the organization and function of DNA. Annu Rev Biophys Biophys Chem $1986,15: 457-475$.

19. Pederson T: Half a century of "the nuclear matrix". Mol Biol Cell 2000, 11:799-805.

20. Coffey DS: Nuclear matrix proteins as proteomic markers of preneoplastic and cancer lesions: commentary re: G. Brunagel et al., nuclear matrix protein alterations associated with colon cancer metastasis to the liver. Clin. Cancer Res., 8: 3039-3045, 2002. Clin Cancer Res 2002, 8:3031-3033.
21. Sjakste N, Sjakste T, Vikmanis U: Role of the nuclear matrix proteins in malignant transformation and cancer diagnosis. Exp Oncol 2004, 26:170-178.

22. Berkhout $B$, Silverman $R H$, Jeang $K T$ : Tat trans-activates the human immunodeficiency virus through a nascent RNA target. Cell 1989 59:273-282.

23. Malim MH, Hauber J, Le SY, Maizel JV, Cullen BR: The HIV-1 rev transactivator acts through a structured target sequence to activate nuclear export of unspliced viral mRNA. Nature 1989, 338:254-257.

24. Zapp ML, Green MR: Sequence-specific RNA binding by the HIV-1 Rev protein. Nature 1989, 342:714-716.

25. Hope TJ, McDonald D, Huang XJ, Low J, Parslow TG: Mutational analysis of the human immunodeficiency virus type 1 Rev transactivator: essential residues near the amino terminus. J Virol 1990, 64:5360-5366.

26. Nekhai $S$, Jeang $K T$ : Transcriptional and post-transcriptional regulation of HIV-1 gene expression: role of cellular factors for Tat and Rev. Future Microbiol 2006, 1:417-426.

27. Cochrane A: Inhibition of HIV-1 gene expression by Sam68 Delta C: multiple targets but a common mechanism? Retrovirology 2009, 6:22

28. Yedavalli VS, Neuveut C, Chi YH, Kleiman L, Jeang KT: Requirement of DDX3 DEAD box RNA helicase for HIV-1 Rev-RRE export function. Cell 2004, 119:381-392

29. Yedavalli VS, Jeang KT: Trimethylguanosine capping selectively promotes expression of Rev-dependent HIV-1 RNAs. Proc Natl Acad Sci USA 2010, 107:14787-14792.

30. Yedavalli VS, Jeang KT: Rev-ing up post-transcriptional HIV-1 RNA expression. RNA Biol 2011, 8:(2):195-9.

31. Felber BK, Hadzopoulou-Cladaras M, Cladaras C, Copeland T, Pavlakis GN: rev protein of human immunodeficiency virus type 1 affects the stability and transport of the viral mRNA. Proc Natl Acad Sci USA 1989, 86:1495-1499.

32. Bray M, Prasad S, Dubay JW, Hunter E, Jeang KT, Rekosh D, Hammarskjold ML: A small element from the Mason-Pfizer monkey virus genome makes human immunodeficiency virus type 1 expression and replication Rev-independent. Proc Natl Acad Sci USA 1994, 91:1256-1260.

33. Neville M, Stutz F, Lee L, Davis LI, Rosbash M: The importin-beta family member $\mathrm{Crm} 1 \mathrm{p}$ bridges the interaction between Rev and the nuclear pore complex during nuclear export. Curr Biol 1997, 7:767-775.

34. Pasquinelli AE, Ernst RK, Lund E, Grimm C, Zapp ML, Rekosh D, Hammarskjold ML, Dahlberg JE: The constitutive transport element (CTE) of Mason-Pfizer monkey virus (MPMV) accesses a cellular mRNA export pathway. EMBO J 1997, 16:7500-7510.

35. Saavedra C, Felber B, Izaurralde E: The simian retrovirus-1 constitutive transport element, unlike the HIV-1 RRE, uses factors required for cellular mRNA export. Curr Biol 1997, 7:619-628.

36. Fornerod M, Ohno M, Yoshida M, Mattaj IW: CRM1 is an export receptor for leucine-rich nuclear export signals. Cell 1997, 90:1051-1060.

37. Fukuda M, Asano S, Nakamura T, Adachi M, Yoshida M, Yanagida M, Nishida E: CRM1 is responsible for intracellular transport mediated by the nuclear export signal. Nature 1997, 390:308-311.

38. Askjaer $P$, Jensen TH, Nilsson J, Englmeier L, Kjems J: The specificity of the CRM1-Rev nuclear export signal interaction is mediated by RanGTP. $J$ Biol Chem 1998, 273:33414-33422.

39. Bear J, Tan W, Zolotukhin AS, Tabernero C, Hudson EA, Felber BK: Identification of novel import and export signals of human TAP, the protein that binds to the constitutive transport element of the type $D$ retrovirus mRNAs. Mol Cell Biol 1999, 19:6306-6317.

40. Strasser K, Bassler J, Hurt E: Binding of the Mex67p/Mtr2p heterodimer to FXFG, GLFG, and FG repeat nucleoporins is essential for nuclear mRNA export. J Cell Biol 2000, 150:695-706.

41. Stutz F, Bachi A, Doerks T, Braun IC, Seraphin B, Wilm M, Bork P, Izaurralde E: REF, an evolutionary conserved family of hnRNP-like proteins, interacts with TAP/Mex67p and participates in mRNA nuclear export. RNA 2000, 6:638-650.

42. Clouse KN, Luo MJ, Zhou Z, Reed R: A Ran-independent pathway for export of spliced mRNA. Nat Cell Biol 2001, 3:97-99.

43. Bolinger $C$, Boris-Lawrie $K$ : Mechanisms employed by retroviruses to exploit host factors for translational control of a complicated proteome. Retrovirology 2009, 6:8 
44. Agutter PS, Richardson JC: Nuclear non-chromatin proteinaceous structures: their role in the organization and function of the interphase nucleus. J Cell Sci 1980, 44:395-435.

45. Nickerson JA, Krockmalnic G, Wan KM, Penman S: The nuclear matrix revealed by eluting chromatin from a cross-linked nucleu. Proc Natl Acad Sci USA 1997, 94:4446-4450.

46. Marcello A, Ferrari A, Pellegrini $\bigvee$, Pegoraro G, Lusic M, Beltram F, Giacca M: Recruitment of human cyclin T1 to nuclear bodies through direct interaction with the PML protein. EMBO J 2003, 22:2156-2166.

47. Marcello A, Lusic M, Pegoraro G, Pellegrini V, Beltram F, Giacca M: Nuclear organization and the control of HIV-1 transcription. Gene 2004, 326:1-11.

48. Dieudonne M, Maiuri P, Biancotto C, Knezevich A, Kula A, Lusic M, Marcello A: Transcriptional competence of the integrated HIV-1 provirus at the nuclear periphery. EMBO J 2009, 28:2231-2243.

49. Belgrader P, Dey R, Berezney R: Molecular cloning of matrin 3. A 125kilodalton protein of the nuclear matrix contains an extensive acidic domain. J Biol Chem 1991, 266:9893-9899.

50. Nakayasu H, Berezney R: Nuclear matrins: identification of the major nuclear matrix proteins. Proc Natl Acad Sci USA 1991, 88:10312-10316.

51. Hisada-Ishii S, Ebihara M, Kobayashi N, Kitagawa Y: Bipartite nuclear localization signal of matrin 3 is essential for vertebrate cells. Biochem Biophys Res Commun 2007, 354:72-76.

52. Zeitz MJ, Malyavantham KS, Seifert B, Berezney R: Matrin 3: chromosomal distribution and protein interactions. J Cell Biochem 2009, 108:125-133.

53. Zhang Z, Carmichael GG: The fate of dsRNA in the nucleus: a p54(nrb)containing complex mediates the nuclear retention of promiscuously Ato-I edited RNAs. Cell 2001, 106:465-475.

54. DeCerbo J, Carmichael GG: Retention and repression: fates of hyperedited RNAs in the nucleus. Curr Opin Cell Biol 2005, 17:302-308.

55. Giordano G, Sanchez-Perez AM, Montoliu C, Berezney R, Malyavantham K, Costa LG, Calvete JJ, Felipo V: Activation of NMDA receptors induces protein kinase A-mediated phosphorylation and degradation of matrin 3. Blocking these effects prevents NMDA-induced neuronal death. J Neurochem 2005, 94:808-818.

56. Salton M, Lerenthal Y, Wang SY, Chen DJ, Shiloh Y: Involvement of matrin 3 and SFPO/NONO in the DNA damage response. Cell Cycle 2010, 9.

57. Lassen KG, Ramyar KX, Bailey JR, Zhou Y, Siliciano RF: Nuclear retention of multiply spliced HIV-1 RNA in resting CD4+ T cells. PLoS Pathog 2006, 2: e68.

58. Patton JG, Porro EB, Galceran J, Tempst P, Nadal-Ginard B: Cloning and characterization of PSF, a novel pre-mRNA splicing factor. Genes Dev 1993, 7:393-406.

59. Zolotukhin AS, Michalowski D, Bear J, Smulevitch SV, Traish AM, Peng R, Patton J, Shatsky IN, Felber BK: PSF acts through the human immunodeficiency virus type $1 \mathrm{mRNA}$ instability elements to regulate virus expression. Mol Cell Biol 2003, 23:6618-6630.

60. Lever $A M$, Jeang $K T$ : Replication of human immunodeficiency virus type 1 from entry to exit. Int J Hematol 2006, 84:23-30.

61. Lever AM, Jeang KT: Insights into Cellular Factors That Regulate HIV-1 Replication in Human Cells. Biochemistry 2011, 50:920-931.

62. Schwartz S, Campbell M, Nasioulas G, Harrison J, Felber BK, Pavlakis GN: Mutational inactivation of an inhibitory sequence in human immunodeficiency virus type 1 results in Rev-independent gag expression. J Virol 1992, 66:7176-7182.

63. Schwartz S, Felber BK, Pavlakis GN: Distinct RNA sequences in the gag region of human immunodeficiency virus type 1 decrease RNA stability and inhibit expression in the absence of Rev protein. J Virol 1992, 66:150-159.

64. Schneider R, Campbell M, Nasioulas G, Felber BK, Pavlakis GN: Inactivation of the human immunodeficiency virus type 1 inhibitory elements allows Rev-independent expression of Gag and Gag/protease and particle formation. J Virol 1997, 71:4892-4903.

65. Shav-Tal Y, Zipori D: PSF and p54(nrb)/NonO-multi-functional nuclear proteins. FEBS Lett 2002, 531:109-114.

66. Kameoka S, Duque $\mathrm{P}$, Konarska MM: p54(nrb) associates with the $5^{\prime}$ splice site within large transcription/splicing complexes. EMBO J 2004 23:1782-1791.

67. Buxade M, Morrice N, Krebs DL, Proud CG: The PSF.p54nrb complex is a novel Mnk substrate that binds the mRNA for tumor necrosis factor alpha. J Biol Chem 2008, 283:57-65.
68. Schwartz S, Felber BK, Benko DM, Fenyo EM, Pavlakis GN: Cloning and functional analysis of multiply spliced mRNA species of human immunodeficiency virus type 1. J Virol 1990, 64:2519-2529.

69. Cochrane AW, Jones KS, Beidas S, Dillon PJ, Skalka AM, Rosen CA: Identification and characterization of intragenic sequences which repress human immunodeficiency virus structural gene expression. J Virol 1991, 65:5305-5313.

70. Maldarelli F, Martin MA, Strebel K: Identification of posttranscriptionally active inhibitory sequences in human immunodeficiency virus type 1 RNA: novel level of gene regulation. J Virol 1991, 65:5732-5743.

71. Nasioulas G, Zolotukhin AS, Tabernero C, Solomin L, Cunningham CP, Pavlakis GN, Felber BK: Elements distinct from human immunodeficiency virus type 1 splice sites are responsible for the Rev dependence of env mRNA. J Virol 1994, 68:2986-2993.

72. Shav-Tal Y, Cohen M, Lapter S, Dye B, Patton JG, Vandekerckhove J, Zipori D: Nuclear relocalization of the pre-mRNA splicing factor PSF during apoptosis involves hyperphosphorylation, masking of antigenic epitopes, and changes in protein interactions. Mol Biol Cell 2001, 12:2328-2340.

73. Cronshaw JM, Krutchinsky AN, Zhang W, Chait BT, Matunis MJ: Proteomic analysis of the mammalian nuclear pore complex. J Cell Biol 2002, 158:915-927.

74. Bushman FD, Malani N, Fernandes J, D'Orso I, Cagney G, Diamond TL, Zhou H, Hazuda DJ, Espeseth AS, König R, Bandyopadhyay S, Ideker T, Goff SP, Krogan NJ, Frankel AD, Young JA, Chanda SK: Host cell factors in HIV replication: meta-analysis of genome-wide studies. PLoS Pathog 2009, 5(5):e1000437.

75. Kula A, Guerra J, Knezevich A, Kleva D, Myers MP, Marcello A: Characterization of the HIV-1 RNA associated proteome identifies Matrin 3 as a nuclear cofactor of Rev function. Retrovirology 2011, 8:60.

doi:10.1186/1742-4690-8-61

Cite this article as: Yedavalli and Jeang: Matrin 3 is a co-factor for HIV-1 Rev in regulating post-transcriptional viral gene expression. Retrovirology 2011 8:61.

\section{Submit your next manuscript to BioMed Central and take full advantage of:}

- Convenient online submission

- Thorough peer review

- No space constraints or color figure charges

- Immediate publication on acceptance

- Inclusion in PubMed, CAS, Scopus and Google Scholar

- Research which is freely available for redistribution

Submit your manuscript at www.biomedcentral.com/submit
C Biomed Central 